\title{
Developing Technological Pedagogical Content Knowledge (TPACK) through Technology-Enhanced Content and Language-Integrated Learning (T-CLIL) Instruction
}

\section{Surattana Adipat ${ }^{1}$ (D)}

Received: 6 April 2021 / Accepted: 20 June 2021 / Published online: 26 June 2021

(c) The Author(s), under exclusive licence to Springer Science+Business Media, LLC, part of Springer Nature 2021

\begin{abstract}
The emergence of innovative technologies and their increased integration in education, especially after the COVID-19 pandemic, has popularized the concept of technological pedagogical content knowledge (TPACK) in the educational field. The aim of this study is to determine whether technology-enhanced content and language-integrated learning (T-CLIL) instruction, which involves integrating technology into the CLIL approach that simultaneously focuses on non-language-related educational content and the target language, can improve the TPACK of preservice English teachers in tertiary education in Thailand. The development of their TPACK was monitored through four subjective tests that were employed at predetermined intervals across the experimental program. Quantitative data obtained from these tests were analyzed using descriptive statistics (mean scores, standard deviations, and percentages), as well as inferential statistics (using a repeated-measures analysis of variance in SPSS). The findings demonstrated that T-CLIL instruction enhances the TPACK of preservice teachers as indicated by the consistent increase in the mean scores for all seven TPACK elements across the four separate time intervals.
\end{abstract}

Keywords Content and language integrated learning · Content knowledge · Pedagogy $\cdot$ Preservice English teachers $\cdot$ Technology $\cdot$ TPACK

\section{Introduction}

Throughout history, pandemics have motivated people to rethink traditional approaches and adopt new outlooks (Cahapay, 2020), and the ongoing Coronavirus Disease 2019 (COVID-19) pandemic is no exception. Educational organizations are currently making preparations for the post-pandemic period, commonly referred

Surattana Adipat

ajsurattana@gmail.com

1 Faculty of Education, Ramkhamhaeng University, Bangkok, Thailand 
to as the "new normal". During this period, as a result of the intense transformations necessitated by the pandemic and the associated governmental and societal responses, the previous status quo or "normal way of doing things" will be replaced by new approaches (Oxford Lexico Dictionary, n.d; Collins English Dictionary, n.d.). This new normal period also presents an opportunity to reconsider educational goals. According to Cahapay (2020), one goal that should be considered in this regard is increasing the relevance, suitability, and responsiveness of curricula to ensure that they remain applicable during future catastrophes, pandemics, and crises. To achieve their common objective of successfully providing education, it is imperative that educational institutions have the ability to continue providing education during all such events. Consequently, in preparation for the "new normal" era, numerous higher-education institutions have sought to exploit existing teaching resources and identify new methods of providing instruction in order to ensure students can continue their learning uninterrupted. Thus, it is clear that the COVID-19 pandemic, which has had a global impact, has caused a comprehensive rethink of the manner by which academic instruction should be implemented.

Various methods of providing uninterrupted education have been adopted across different countries, but a common trend during the COVID-19 pandemic is the growth of distance learning (United Nations Educational, Scientific and Cultural Organization, 2020). Essentially, educational organizations around the world, seeking to effectively administer their curricula to students, are considering responsive strategies that incorporate technology. Implementing technology in the educational context can help transform raw information into knowledge, and facilitate education, relevant learning, relationships between instructors and learners, and their methods of communication (Pimmer et al., 2016; Ponce Gea et al., 2021; Tondeur et al., 2017). Further, attempts to broaden the scope of technology in the area of teacher education have also increased in scale (Dziuban et al., 2018). If educational establishments plan to reopen their doors in the next academic year, it is essential that they develop effective strategies to ensure that their teachers have the ability to provide students with quality education during the new normal period (Tria, 2020). Consequently, teachers must possess sufficient digital competence to master information and communication technologies and integrate them into their learning and teaching processes (Hatlevik et al., 2018).

As a result of the continued development of innovative technologies and their increased integration in educational practices, the concept of "technological pedagogical content knowledge" (previously abbreviated to "TPCK," but now defined as "TPACK") is increasing in prevalence in the educational field (Agyei \& Keengwe, 2014; Smith et al., 2016; Stoilescu, 2015). TPACK comprises of seven elements (content knowledge [CK], pedagogical knowledge [PK], technological knowledge [TK], pedagogical content knowledge [PCK], technological content knowledge [TCK], and TPACK itself), and is primarily based on the theory that a teacher's proficiency in each constituent element for a given learning context determines the effectiveness of their ability to integrate technology into the associated education. This suggests that to integrate technologies in the teaching of, for example, English, the context in which the learning occurs and the particular attributes of English that the given technology can support must be considered. Thus, teachers' existing and interdependent 
understanding of content, overall pedagogy, technology, and learning contexts have significant value (Harris \& Hofer, 2011), even in the context of traditional teaching in a classroom environment (Archambault \& Barnett, 2010). Additionally, incorporating technology, suitable teaching techniques, and instructional practices can facilitate the creation of genuine, engaging, and collaborative learning environments, which enable students to improve their learning and develop new skills that can be used to negotiate the dynamic issues and environments associated with globalization (Hastings \& Tracey, 2005; Kivunja, 2014; Mehlinger \& Powers, 2002; Son et al., 2017).

In the context of TPACK, the main goal is to train preservice teachers to develop sufficient technological literacy; such training should enable them to obtain proficiency in delivering multiple learning approaches, including face-to-face learning, blended learning, distance learning, and home-schooling (McGarr \& McDonagh, 2019). Further, teachers should also acquire the ability to deliver and present their knowledge in various specific situations or contexts in their classrooms. In particular, it is essential that teachers are cognizant of the three main components at the core of effective teaching (content, pedagogy, and technology) and how these three components are interconnected.

In the context of teaching English to non-native English speakers, to ensure that educators receive a high standard of training and possess sufficient professional competence, the TESOL International Association has established standards for the different aspects of English-language teaching. As stipulated in the TESOL International Association's 2010 TESOL/NCATE Standards for the Recognition of Initial TESOL Programs in P-12 Teacher Education and 2018 Standards for Initial TESOL Pre-K-12 Teacher Preparation Programs (TESOL International Association, 2010, 2019), preservice teachers must learn how to access the necessary content and develop the necessary pedagogical understanding and proficiencies required to teach learners of English. In particular, these teachers must be able to show that they are knowledgeable of the structures of the English language, how it is used, the process of acquiring and developing a second language, and the language processes that act as language models for learners. Further, they should be able to enable and evaluate students' English-language learning and assist them in acquiring academic language and literacy elements unique to particular content fields. Moreover, preservice teachers must also establish environments that are supportive and positive, prepare and apply standards-based teaching according to evidence-based, student-oriented, interactive strategies; adapt their teaching to the needs of their learners; grade learners' level and proficiency of English; and utilize and adjust associated resources, such as technology, to effectively plan, develop, implement, and communicate educational materials.

TESOL's technology standards framework for educators in both preservice and inservice environments, which is specifically related to the teaching of the English language, emphasizes the integration of technology into education. It suggests that such incorporation of technologies into teaching pedagogy is necessary not only for facilitating the effective acquisition of English as a second language, but also for developing students' electronic-literacy proficiency (Healey et al., 2011; Healey et al., 2008).

To ensure the quality and promote ongoing enhancement of P-12 student learning, the Council for Accreditation of Educator Preparation (CAEP) developed the 
2013 and 2022 CAEP standards, which stipulate that teacher-education programs must strengthen teachers' content knowledge, pedagogical understanding, and proficiency. This suggests that education programs for teachers should foster preservice teachers' content knowledge, pedagogical awareness and proficiencies, critical dispositions, ability to perform their professional duties, and capabilities in terms of effectively integrating technology into their teaching (Council for the Accreditation of Educator Preparation, 2013, 2020). In other words, to ensure that quality and evidence-based education can be provided to students, teachers' proficiencies in both pedagogy and technology should be strengthened (Basilaia \& Kvavadze, 2020).

In addition to international standards, from a national perspective the Thai Qualifications Framework for Higher Education suggests that it is essential that, during training programs, preservice teachers, along with receiving knowledge, are given opportunities to apply their skills. Such an approach, through helping preservice teachers develop experience of integrating knowledge regarding the target language into lessons plans, applying theories and principles of language teaching to instructional management, and suitably incorporating information and digital technologies into teaching environments, could contribute to enhancing teachers' TPACK (Office of the Higher Education Commission, 2019).

Although a range of standards for teacher-education programs have been developed to establish and strengthen preservice teachers' professional abilities, problems remain in relation to the quality of education preservice teachers provide (Aldeman et al., 2011). It is frequently observed that some teachers lack the skills of integrating suitable methodologies and providing quality education, which indicates that teacher-education programs are unable to accomplish their main goal of enhancing the competencies of preservice teachers (Fadhilah, 2018; Larson, 2014; Moon, 2014). It has been suggested that the primary obstacles preventing such teachers from teaching effectively are a lack of confidence in their ability of utilizing technology, and insufficient knowledge of pedagogically robust approaches for incorporating technology into curricula ( $\mathrm{Ng} \&$ Nicholas, 2013). As mentioned by Garzón Artacho et al. (2020), the quality of education is determined by teachers' training. The association among quality, learning, and technology is dependent on how these components are incorporated into the training process; new techniques and approaches that can be implemented to enhance teaching processes are constantly being sought.

Therefore, the aim of the current study was to enhance knowledge in each of the TPACK domains, among a sample of preservice teachers in tertiary education in Thailand, through the implementation of technology-enhanced content and language-integrated learning (T-CLIL) instruction. There are two main reasons technology-integrated CLIL was chosen for this research: 1) CLIL, which primarily aims to increase students' proficiency in a second language while concurrently developing students' knowledge and abilities in a non-language subject, is regarded as being particularly effective for teaching the English language (Akyuz, 2018; Coyle, 2005; Marsh, 2015; Montalto et al., 2016; Pavesi et al., 2001), and 2) it has been determined that technology, through providing a range of instruments that can be employed to enable learning, can potentially encourage teaching innovation (Almekhlafi \& Almeqdadi, 2010). Thus, T-CLIL was applied in this research based on the assumption that it would facilitate the development of preservice teachers' 
TPACK, a skillset that is necessary for effective teaching, understanding students' attributes and English language knowledge, and recognizing the pedagogical approaches that facilitate the constructive incorporation of technologies in English language teaching (ELT).

\section{Content and language integrated learning}

The European Network of Administrators, Researchers, and Practitioners first adopted CLIL in the mid-1990s (Marsh, 2002), and the majority of the countries in Europe have now integrated this approach into their educational systems (Wolff, 2012). CLIL has also recently been adapted in Asian countries, and this use of CLIL in Asia, where English is predominantly a secondary language, could provide valuable insights into the potential effectiveness of this technique for ELT (Lasagabaster \& Sierra, 2010).

CLIL features a dual-focus approach to education; specifically, it involves concurrent learning of a target language and an educational subject (referred to as "content"), with the aim of developing students' mastery of both the language and content to predetermined levels (Juan-Garau \& Salazar-Noguera, 2015; Maljers et al., 2010). In this approach, a foreign or supplementary language is used to teach a subject that is unrelated to the language, with the approach being structured to allow the content and language education to complement each other. Essentially, CLIL presents a continuum in which the language and content have the same weight. The basic principles of CLIL are based on the premise that language is used for learning and communicating, meaning its role in learning specific content is critical. This fundamental assumption affects the teaching approaches used in classrooms because the aim is not only to provide education in a different language, but also to focus on the language itself (Coyle et al., 2010).

CLIL can be considered a novel learning and education approach that promotes linguistic diversity. It can be applied in various ways and in significantly distinct contexts, as it affords numerous different types of teaching. CLIL can be used to teach a single or multiple topics throughout the academic year, for a module on a particular subject, or as a component of a normal course. When introducing CLIL, it may be necessary to partially adjust traditional approaches to teaching the language or content in question, or to adjust the time frame at which certain elements are introduced to students. In particular, for teachers, when developing and implementing CLIL, the most challenging factor is its integrative essence; this applies to all educational levels, ranging from primary to adult (C4C - CLIL for Children, 2016).

Naves (2002) stated that, for CLIL teaching strategies to be effective, teachers must apply active teaching behaviors, such as delivering instructions with clarity, precisely explaining tasks, sustaining focus on the learning task, facilitating a suitable learning pace, and presenting the materials students require. To increase the comprehensibility of the input and embedded context, approaches such as demonstrating, outlining, utilizing visuals, building redundancy, rephrasing, scaffolding, and connecting new knowledge to students' existing knowledge should also be used. 


\section{Methodology}

In this study, a single-group time-series design was employed, as its primary purpose was to find out whether the treatment influences behavior development or how the target behaviors improve over time (Kaplan \& Glass, 1995). In this study, four test measurements were used to assess the development of TPACK, over a 13-week period, among a sample of preservice English teachers in tertiary education in Thailand who received T-CLIL instruction. T-CLIL represented a paradigm in which, the three main knowledge domains of technology, pedagogy, and content, were simultaneously integrated (Mishra \& Koehler, 2006).

\subsection{Participants}

All participants were recruited from an English Teaching Essentials course, which primarily focused on developing in preservice teachers the necessary classroom skills required prior to commencing their teaching internships. A simple randomsampling technique was used, with emphasis on preservice teachers who regularly attended class, submitted assignments, and achieved sufficient grades in this program. Of the 48 preservice teachers enrolled in the course, 30 who had complete attendance were chosen. These individuals were then informed of this study's aim, which was to examine how a new approach would impact their teaching abilities, and of the processes to be implemented. All participants gave their approval to participate and signed consent forms.

\subsection{Research instruments}

\subsubsection{Lesson plans}

Lesson plans were designed to provide the preservice teachers with information on subjects such as learner attributes, the media and technology employed in ELT (e.g., web-conferencing technologies, online/offline evaluation instruments), instructional approaches/methods/techniques, the national core curriculum for fundamental education, classroom action research, English-lesson planning, tests and assessments, teaching practice in classroom environments, and virtual teaching activities. All lesson plans were designed based on the T-CLIL approach (i.e., the material was presented in English), and the duration of each lesson was approximately five hours, amounting to a total course duration of 45 hours (nine lessons).

For instance, in one of the lessons, the preservice teachers were taught about a teaching method named Task-Based Language Teaching (TBLT) via Zoom videoconferencing. During this instruction, they attended a lecture on TBLT's basic aspects, watched the researcher's demonstration, participated in TBLT activities, and then practiced writing a TBLT lesson on their own. Specifically, during the lecture, they learned basic aspects of TBLT such as its objective, primary stages of pre-task, task cycle (task, planning, and reporting), language focus, types of 
tasks and sub-tasks, and criticism, etc. As TBLT is not monolithic, it does not constitute one single methodology. During the demonstrations and activities, the researcher presented how other teaching methods or approaches, such as cooperative language learning (CLL) and game-based learning, can be employed in the TBLT lesson, and conducted TBLT activities with them. For example, the researcher set up the breakout room function in Zoom, manually assigned five students into each breakout room (mixed-ability home groups), and created one room as an expert group. Each participant from each "home" breakout room was moved into the "expert" breakout room, where they listened to a part of an ongoing story until the end of the story. After getting the information, they went back to their "home" breakout rooms to share what they heard, so that each group could gather all the details and understand the whole story. Then the researcher assessed their comprehension through GoFormative, Quizizz, Quizalize, or Flippity.

After the researcher's lecture, demonstration, and activities, the preservice teachers practiced creating their own TBLT lessons incorporating an interactive PowerPoint using Google slides with the Nearpod add-on. This would provide their prospective students the opportunity to be exposed to the target language, use it to express meaning, become motivated to engage and use what they know, and focus on language form to prevent fossilization, in accordance with the TBLT optimum conditions of language learning. Therefore, by the end of the instruction, the preservice teachers could gain knowledge of the language by listening and using English meanwhile improving their pedagogical and technology skills and successfully achieving the integration of TPACK.

More importantly, prior to the implementation of lesson plans with the preservice teachers, the lesson content was assessed for accuracy and appropriateness. Five specialists who had expertise in English language teaching, course design, and/or curriculum and instruction design, conducted evaluations of each lesson plan using a five-point rating scale, ranging from "strongly agree (5)" to "strongly disagree (1)." They responded to a form consisting of six main Sects. (15 subitems): 1] rationale (It clearly states the main concept of the lessons; and the intended outcomes of the instruction), 2] learning objectives (They indicate what students would be expected to attain by the end of instruction; and are observable and measurable), 3] course content (It is relevant to predetermined learning objectives; it should be up-to-date), 4] instructional activities (They are relevant to T-CLIL; relevant to research objectives; enable the students to achieve the learning outcomes; are practical; and fit into the allocated time), 5] technology (It is relevant to the content; enhances students' TPACK; is interesting, which can motivate and maintain students' interest), and 6] assessment and evaluation (They are relevant to learning objectives). In addition, there was an open-ended question allowing the experts to provide additional suggestions or comments. The evaluation results from the experts indicated that all lesson plans were suitable, as they all received comparably high scores (range: 4.77-4.93), which were interpreted based on the following intervals: 4.21-5.00 (strongly agree), 3.41 to 4.20 (agree), 2.61 to 3.40 (neither agree nor disagree), 1.81 to 2.60 (disagree), and 1.00 to 1.80 (strongly disagree) (Kan, 2009). 


\subsubsection{Tests and rubrics}

In the experimental research process, four subjective tests were designed to assess the evolution of the participants' TPACK during the course. These tests were administered at the start, during (on two occasions), and upon completion of the T-CLIL program. Each of the subjective tests comprised a single test item in which the participants were asked to develop a plan for a lesson lasting three hours that incorporated appropriate teaching techniques, approaches, methods, and technologies for teaching English content.

Across the four tests, the analytic scoring rubrics described below were utilized to assess the seven elements of TPACK.

1. CK - This comprised four criteria: content, organization, vocabulary, and grammar.

2. PK - Four criteria: lesson-plan framework, quality of developed questions, teaching approaches, and evaluation.

3. TK - Four criteria: general cognizance of computer hardware, general cognizance of computer software, ability to solve technical problems, and awareness of specific technology.

4. PCK - Four criteria: teaching techniques, activities, instructional resources, and evaluation and feedback.

5. TCK - Four criteria: understanding of the use of technology to verify language accuracy, understanding of the use of technology for conducting quality research on content, awareness of how technology can be used to represent content, and cognizance of plagiarism when utilizing extant resources/contents.

6. TPK - Four criteria: integration of technology, instructing students on avoidance of plagiarism, managing classrooms, and evaluation.

7. TPACK - Four criteria: using suitable teaching methods and technologies to present content, implementing activities through the use of suitable teaching methods and technologies for developing English proficiency, implementing activities through the use of suitable teaching methods and technologies for developing students' understanding of additional English-language elements, and using suitable teaching methods and technologies for evaluating students' performances.

Identical four-point scoring scales were used for each of the rubrics described above ( 1 = "limited," 2 = "developing," 3 = "proficient," and $4=$ "exemplary"); a definition was included below every criterion, along with a scoring scale indicating the performance criteria for each score on the four-point range. Each participant's overall score was calculated by summing the scores awarded for each criterion in each rubric (the score range for each rubric was 1-16).

The same five experts who evaluated the lesson plans were asked to evaluate the test items and rubrics and report the extent to which they believed these items and rubrics corresponded with the elements they were intended to measure. Consequently, the index of item-objective congruence was 1.0, indicating good validity. Additionally, inter-rater reliability was evaluated by applying the following process: 
in a pilot study, four subjective TPACK-assessment tests comprising one item each were given to 30 students; two assessors then conducted assessments of these tests. Cronbach's alpha coefficients for all four tests with the same set of seven rubrics were calculated as $\alpha=0.902,0.896,0.900$, and 0.896, respectively, indicating acceptable reliability with statistically significant differences $(\mathrm{p} \leq 0.01)$.

\subsection{Data collection and analysis}

The data were collected across a period of four months at a university in Thailand via unstructured observations of classroom activities that were video-recorded. Four tests were administered to the participants at three specific time intervals:

1. Before the study: The initial test, which was intended to ascertain the participants' baseline TPACK levels, was administered to the participants on the first day of the program, prior to the implementation of the T-CLIL instruction.

2. While the study was in progress: Tests two and three were administered during the $5^{\text {th }}$ and $9^{\text {th }}$ weeks of the program, respectively.

3. Upon completion of the study: The final test was administered during the final session of the program $\left(13^{\text {th }}\right.$ week).

Seven analytical rubrics were used to score the four different tests; these rubrics reflected the seven different elements of TPACK (CK, PK, TK, PCK, TCK, TPK, and TPACK, respectively). The overall scores for the tests were calculated based on the scores awarded for each criterion contained in the rubrics. Two assessors evaluated the test items, the researcher and an additional assessor, both of whom used identical rubrics; any disagreements regarding scores were resolved through discussions.

Analysis of the quantitative data generated was performed using descriptive statistics (mean scores, standard deviations, and percentages). Meanwhile, to verify the hypothesis that T-CLIL enhances the TPACK of preservice teachers, inferential statistics were analyzed using a repeated-measures analysis of variance (ANOVA) in SPSS.

\subsection{Ethical considerations}

Ethical factors were taken into careful consideration during this research. The participants were informed of the researcher's plan to assess the development of their TPACK and of the processes that would be implemented during the program. All participants were given a consent form, which included the title of the research, the researcher's background, the aim of the research, and details regarding the research process, possible risks, and the expected gains that participation in the research would bring. Further, the form also informed the participants that their data would remain confidential, that they could refuse to participate or could withdraw from the research at any point without penalty, and that they could question the researcher about aspects of the study. They were then given adequate time 
before the program commenced to decide whether they would like to participate and to sign the consent form. Participants were given assurances that if they declined to participate their future grades would not be impacted, nor would their relationship with the researcher. It was specifically highlighted that any artefacts submitted, or data recorded in the collection process would remain confidential; such data would be saved securely on a file protected by password. Access to these data would only be available to the researcher and the additional evaluator, and they could only be utilized for educational research. Additionally, participants were informed that their identities would not be revealed when the study findings were reported.

\section{Results}

The following section presents the experimental results acquired from the four tests administered during the $1^{\text {st }}, 5^{\text {th }}, 9^{\text {th }}$, and $13^{\text {th }}$ sessions, respectively, of the program. Figure 1 visually represents the distributions of the overall mean scores increase of scores for the seven TPACK components across the four tests, with the score range of 1-16 for each rubric.

The data presented in Fig. 1 show that the participants' scores for each of the seven elements of the TPACK framework increased continually throughout the T-CLIL program. It is particularly notable that this increase in mean scores applied to all seven elements across all four time intervals. The changes in each element are described in detail below.

1. CK: From Test $1(M=5.63, S D=1.81)$ to Test $2(M=5.77, S D=1.77)$, there was a marginal increase in the mean score and standard deviation. This increase became slightly more pronounced in Test $3(\mathrm{M}=6.70, \mathrm{SD}=2.12)$, before becoming even more evident in Test $4(\mathrm{M}=8.90, \mathrm{SD}=2.90)$, with the percentage of scores increasing from $35.18,36.06,41.87$, to 55.62, respectively.

2. PK: From Test $1(\mathrm{M}=5.23, \mathrm{SD}=1.52)$ to Test $2(\mathrm{M}=5.40, \mathrm{SD}=1.50)$, the mean score and standard deviation marginally increased, and a more pronounced increase was observed in Test $3(\mathrm{M}=6.43, \mathrm{SD}=2.11)$. The increase in the mean

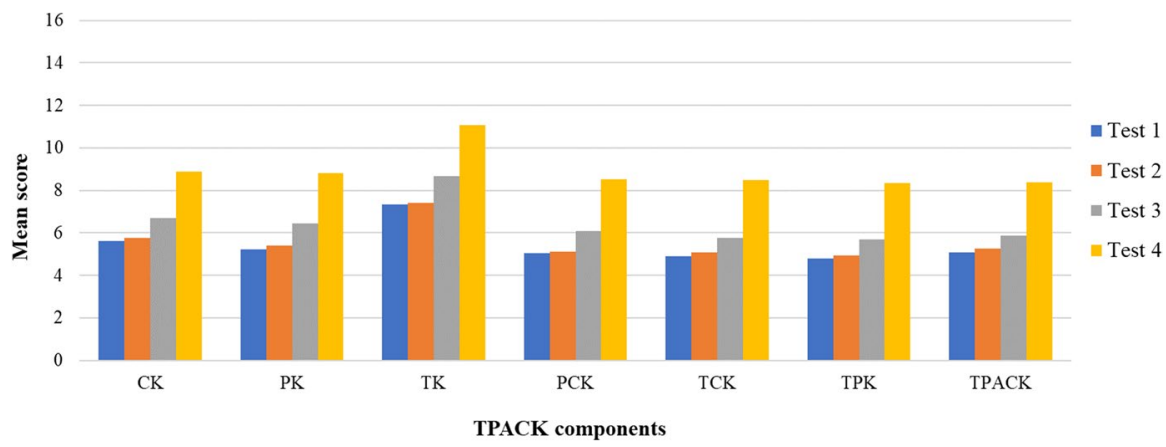

Fig. 1 Overall mean scores for the seven TPACK components across the four tests $(\mathrm{N}=30)$ 
score was even more evident in Test $4(\mathrm{M}=8.83, \mathrm{SD}=3.04)$, with the percentage of scores increasing from $32.68,33.75,40.18$, to 55.18 , respectively.

3. TK: From Test $1(\mathrm{M}=7.33, \mathrm{SD}=1.49)$ to Test $2(\mathrm{M}=7.40, \mathrm{SD}=1.48)$, there was a modest upward trend in the mean score and standard deviation. This became more evident in Test $3(\mathrm{M}=8.67, \mathrm{SD}=1.99)$, and even more noticeable in Test $4(\mathrm{M}=11.07, \mathrm{SD}=3.06)$, with the percentage of scores increasing from 45.81 , $46.25,54.18$, to 69.18 , respectively.

4. PCK: From Test $1(\mathrm{M}=5.03, \mathrm{SD}=1.47)$ to Test $2(\mathrm{M}=5.13, \mathrm{SD}=1.50)$, there was a marginal increase in the mean score and standard deviation, which became more pronounced in Test $3(\mathrm{M}=6.07, \mathrm{SD}=2.18)$. Meanwhile, the score in Test 4 showed a considerable increase $(\mathrm{M}=8.53, \mathrm{SD}=3.12)$. The percentage of scores increased from $31.43,32.06,37.93$, to 53.31 , respectively.

5. TCK: From Test $1(M=4.90, S D=1.16)$ to Test $2(M=5.10, S D=1.32)$, the mean score and standard deviation showed insignificant increases; these became more pronounced in Test $3(\mathrm{M}=5.77, \mathrm{SD}=2.01)$. A significant increase was observed in Test $4(\mathrm{M}=8.50, \mathrm{SD}=2.91)$. The percentage of scores increased from $30.62,31.87,36.06$, to 53.12 , respectively.

6. TPK: From Test $1(\mathrm{M}=4.80, \mathrm{SD}=1.16)$ to Test $2(\mathrm{M}=4.93, \mathrm{SD}=1.23)$, there was a slight increase in the mean score and standard deviation, which became more pronounced in Test $3(\mathrm{M}=5.70, \mathrm{SD}=1.99)$. In Test 4 , a significant increase was observed $(\mathrm{M}=8.33, \mathrm{SD}=3.09)$. The percentage of scores increased from $30.00,30.81,35.62$, to 52.06 , respectively.

7. TPACK: From Test $1(\mathrm{M}=5.10, \mathrm{SD}=1.47)$ to Test $2(\mathrm{M}=5.27, \mathrm{SD}=1.57)$, there was a marginal increase in the mean score and standard deviation, which became more discernible in Test $3(\mathrm{M}=5.87, \mathrm{SD}=2.08)$. A significant increase was observed in Test $4(\mathrm{M}=8.40, \mathrm{SD}=3.17)$. The percentage of scores increased from $31.87,32.93,36.68$, to 52.50 , respectively.

To test the hypothesis that the participants' TPACK could be enhanced by T-CLIL instruction, a repeated-measures ANOVA was performed. The results are shown in Table 1.

As illustrated in Table 1, the repeated-measures ANOVA revealed that the scores for each of the TPACK components showed significant differences across the program. The results for all seven TPACK framework components are shown below.

1. The results for the CK component differed statistically (at the 0.05 significance level) between at least two time points, with a large effect size $(\mathrm{F}=44.292$, $\mathrm{df}=1.520,44.084, \mathrm{p}=0.000$, partial eta squared [effect size] $=0.604$ ).

2. The results for the PK component differed statistically (at the 0.05 significance level) between at least two time points, with a large effect size $(\mathrm{F}=50.998$, $\mathrm{df}=1.263,36.628, \mathrm{p}=0.000$, partial eta squared [effect size] $=0.637$ ).

3. The results for the TK component differed statistically (at the 0.05 significance level) between at least two time points, with a large effect size ( $\mathrm{F}=53.852$, $\mathrm{df}=1.222,35.430, \mathrm{p}=0.000$, eta squared [effect size] $=0.650)$. 
Table 1 Results of a repeatedmeasures ANOVA regarding differences in the mean scores of the seven TPACK components across the four tests (Greenhouse-Geisser test)

\begin{tabular}{llrrll}
\hline Study & SS & \multicolumn{1}{l}{ Df } & \multicolumn{1}{l}{ MS } & F & Effect size \\
\hline CK & 205.167 & 1.520 & 134.965 & $44.292^{*}$ & .604 \\
Error (CK) & 134.333 & 44.084 & 3.047 & & \\
PK & 247.825 & 1.263 & 196.216 & $50.998^{*}$ & .637 \\
Error (PK) & 140.925 & 36.628 & 3.848 & & \\
TK & 273.967 & 1.222 & 224.247 & $53.852^{*}$ & .650 \\
Error (TK) & 147.533 & 35.430 & 4.164 & & \\
PCK & 238.825 & 1.326 & 180.061 & $44.850^{*}$ & .607 \\
Error (PCK) & 154.425 & 38.464 & 4.015 & & \\
TCK & 249.200 & 1.550 & 160.814 & $47.765^{*}$ & .622 \\
Error (TCK) & 151.300 & 44.939 & 3.367 & & \\
TPK & 242.958 & 1.381 & 175.886 & $38.651^{*}$ & .571 \\
Error (TPK) & 182.292 & 40.059 & 4.551 & & \\
TPACK & 210.758 & 1.399 & 150.635 & $37.270^{*}$ & .562 \\
Error (TPACK) & 163.992 & 40.575 & 4.042 & & \\
\hline
\end{tabular}

${ }^{*} p$-value $\leq .05$

CK: content knowledge; df: degrees of freedom; F: F ratio; MS: mean squares; PCK: pedagogical content knowledge; PK: pedagogical knowledge; SS: sum of squares; TCK: technological content knowledge; TK: technological knowledge; TPACK: technological pedagogical content knowledge; TPK: technological pedagogical knowledge

4. The results for the PCK component differed statistically (at the 0.05 significance level) between at least two time points, with a large effect size $(F=44.850$, $\mathrm{df}=1.326,38.464, \mathrm{p}=0.000$, eta squared [effect size] $=0.607$ )

5. The results for the TCK component differed statistically (at the 0.05 significance level) between at least two time points, with a large effect size $(\mathrm{F}=47.765$, $\mathrm{df}=1.550,44.939, \mathrm{p}=0.000$, eta squared [effect size] $=0.622$ )

6. The results for the TPK component differed statistically (at the 0.05 significance level) between at least two time points, with a large effect size $(\mathrm{F}=38.651$, $\mathrm{df}=1.381,40.059, \mathrm{p}=0.000$, eta squared [effect size] $=0.571$ )

7. The results for the TPACK component differed statistically (at the 0.05 significance level) between at least two time points, with a large effect size $(\mathrm{F}=37.270$, $\mathrm{df}=1.399,40.575, \mathrm{p}=0.000$, eta squared [effect size] $=0.562$ ).

\section{Discussion and conclusion}

The results presented in this paper prove the hypothesis that preservice English teachers' TPACK can be enhanced through T-CLIL instruction. This is evidenced by the gradual increase in the mean scores for each of the seven TPACK components across the four time intervals of the program, from the initial to the final test. Notably, the mean scores of virtually all participating preservice teachers increased after the T-CLIL instruction was implemented. This suggests that the T-CLIL approach offers 
clear benefits for preservice English teachers. In particular, the findings show that administering CLIL that focused on content related to providing education enabled the participants to utilize a range of vocabulary and sentence structures when performing their tasks; this accords with the findings of Juan-Garau and Salazar-Noguera (2015). Furthermore, it was found that integrating technology in CLIL has an impact on the learning-teaching procedure, which concurs with Pimmer et al. (2016).

It could be suggested that the learning provided through the T-CLIL instruction was mediated by the usage of content that was usable and relatable to the participants. The educational program administered in this research incorporated topics associated with the teaching of the English language, which were relatable to the preservice teachers; this is in complete agreement with Wolff (2012) and Marsh (2015), who emphasized the use of relevant content to facilitate the learning of a language. The test results for the present research clearly show that the experimental program, in which the teaching of particular content was combined with instruction on the language itself and students were enabled to practically apply the material immediately, as suggested by Akyuz, 2018; Coyle, 2005, Coyle et al., 2010; Marsh, 2015; Montalto et al., 2016; Pavesi et al., 2001), was successful. The lesson plans the participants prepared during the tests revealed that they had mastered multiple content dimensions, including the process of writing lesson plans that incorporate all necessary components (such as objectives, activities, and evaluations) and methods of including in lesson plans suitable pedagogical approaches and technologies that facilitate learning of the subject matter.

The findings also show that individual components ( $\mathrm{CK}, \mathrm{PK}$, and TK) can be developed more effectively than integrated components (PCK, TCK, TPK, and TPACK). This accords with the conclusions of Koehler and Mishra (2009), who found that obtaining TPACK is not the same as having separate knowledge of content, pedagogy, and technology, respectively; to deliver meaningful and highly proficient teaching, it is necessary to simultaneously integrate each component. Good results were observed in terms of TK, which was significantly acquired. It should be emphasized, however, that the preservice teachers' demonstration of TK was superior to that of TPACK because, for TPACK, they were required to show how such skills could be applied in the teaching of English. Examples of such application include incorporating into lessons an online picture book (StoryJumper) or animation (Powtoon), or using the "breakout rooms" function of Zoom to create expert and home groups for the Jigsaw cooperative language learning activity; further, evaluations of students' understanding could be performed using online assessment tools (e.g., QuizWhizzer, Flippity, Blooket, e-learning Plickers, Quizalize, Quizizz, Quizlet, GoFormative, and GamiLab), infographic tools (Canva, Piktochart, etc.), or mind-map tools (MindMeister, Coggle, etc.). It can be inferred from the above findings that the process of integrating TPACK into practice can be lengthy, which is consistent with the results of Yu and Golden (2019).

In conclusion, the overall findings of the present study demonstrate that T-CLIL is capable of enhancing the TPACK of preservice teachers. The critical factor in this process is not the intense application of technological resources, but whether appropriate pedagogical approaches and technologies are used. It is important to note that these findings show that the T-CLIL instruction should 
be designed and systematically implemented such that preservice teachers can observe, through modeling, how content, language, and technology can be appropriately integrated. Furthermore, in teacher-education programs the preservice teachers should be provided with opportunities to have real-life classroom experiences that allow them to explore how technology can be used to support pedagogical goals. Practical application of content helps them successfully acquire TPACK and will improve their comprehension of how the appropriate use of technology can enhance pedagogical approaches that positively affect how learners engage with and retain content.

\section{Limitations of the study}

This study had some limitations. Firstly, low-proficient preservice teachers encountered difficulties in using the target language because not all of them were equally proficient in English language skills. Furthermore, the preservice teachers whose academic language abilities were below that of their peers required additional support to attain a suitable academic standard. Even after a five-hour-lesson, some teachers required additional time with the trainer, which highlighted the limitation of time constraint.

\section{Recommendations for future research}

As there is a requirement for all preservice teachers to take a written examination as well as to participate in teaching practice in the classroom in Thailand, researchers can explore the connection between the scores obtained in the examination and the standard of the preservice teacher's teaching practice. Ascertaining the ability of preservice teachers, during micro-teaching, to plan lessons and to give instruction, will enable researchers to amend the instruction or lessons in order to adjust them, thus allowing teacher trainers to better equip the preservice teachers with the capability to synthesizing their understanding of second language acquisition and language teaching pedagogy in accordance with their knowledge of their learners, the curriculum, and the teaching context. This can guarantee that they can envisage the desired learning and analyze how the elements of such learning should be combined. It can provide a real vision in the classroom in order to obtain more profound knowledge under carefully controlled conditions. Moreover, a long-term follow-up studies on preservice teachers can be undertaken during their internships. This would indicate if the learning benefits of T-CLIL were retained in the participants, and if the teachers could utilize TPACK in practical teaching contexts. Apart from conducting the study with the preservice teachers, future researchers can also conduct such studies with in-service teachers (both experienced and novice) in order to investigate their TPACK. 


\section{References}

Agyei, D. D., \& Keengwe, J. (2014). Using technology pedagogical content knowledge development to enhance learning outcomes. Education and Information Technologies, 19, 155-171.

Akyuz, D. (2018). Measuring technological pedagogical content knowledge (TPACK) through performance assessment. Computers \& Education, 125, 212-225.

Aldeman, C., Carey, K., Dillon, E., Miller, B., \& Silva, E. (2011). A measured approach to improving teacher preparation. Education Sector.

Almekhlafi, A. G., \& Almeqdadi, F. A. (2010). Teachers' perceptions of technology integration in the United Arab Emirates school classrooms. Educational Technology \& Society, 13(1), 165-175.

Archambault, L. M., \& Barnett, J. H. (2010). Revisiting technological pedagogical content knowledge: Exploring the TPACK framework. Computers and Education, 55(4), 1656-1662.

Basilaia, G., \& Kvavadze, D. (2020). Transition to online education in schools during a SARS-CoV-2 Coronavirus (COVID-19) pandemic in Georgia. Pedagogical Research, 5(4), 1-9.

Cahapay, M. B. (2020). Rethinking education in the new normal post-COVID-19 era: A curriculum studies perspective. Aquademia, 4(2), ep20018, 1-5

Council for the Accreditation of Educator Preparation. (2013). CAEP accreditation standards and evidence: Aspirations for educator preparation. Author.

Council for the Accreditation of Educator Preparation. (2020). 2022 CAEP accreditation standards. Author.

Coyle, D. (2005). CLIL: Planning tools for teachers. University of Nottingham.

Coyle, D., Hood, P., \& Marsh, D. (2010). CLIL: Content and language integrated learning. Cambridge University Press.

C4C - CLIL for Children. (2016). State of art report about use of CLIL methodology in primary schools. Retrieved 20 July, 2020 from http://www.clil4children.eu/wp-content/uploads/2016/07/ C4C_State_of-the-Art_Report_v01.pdf.

Dziuban, C., Graham, C. R., Moskal, P. D., Norberg, A., \& Sicilia, N. (2018). Blended learning: The new normal and emerging technologies. International Journal of Educational Technology in Higher Education, 15(3), 1-6.

Fadhilah, E. (2018). Rethinking the Maintenance of CLT in Indonesia: A Response to Ariatna's “The Need for Maintaining CLT in Indonesia." TESOL Journal, 9(1), 224-236.

Garzón Artacho, E., Martínez, T. S., Ortega Martín, J. L., Marín Marín, J. A., \& Gómez García, G. (2020). Teacher training in lifelong learning-The importance of digital competence in the encouragement of teaching innovation. Sustainability, 12(7), 2852.

Harris, J. B., \& Hofer, M. (2011). Technological pedagogical content knowledge (TPACK) in action. Journal of Research on Technology in Education, 43(3), 211-229.

Hastings, N. B., \& Tracey, M. W. (2005). Does media affect learning: Where are we now? TechTrends, 49(2), 28-30.

Hatlevik, O. E., Throndsen, I., Loi, M., \& Gudmundsdottir, G. B. (2018). Students' ICT self-efficacy and computer and information literacy: Determinants and relationships. Computers \& Education, $118,107-119$.

Healey, D., Hanson-Smith, E., Hubbard, P., Ioannou-Georgiou, S., Kessler, G., \& Ware, P. (2011). TESOL technology standards: Description, implementation, integration. TESOL.

Healey, D., Hegelheimer, V., Hubbard, P., Ioannou-Georgiou, S., Kessler, G., \& Ware, P. (2008). TESOL technology standards framework. TESOL.

Juan-Garau, M., \& Salazar-Noguera, J. (Eds.). (2015). Content-based language learning in multilingual educational environments. Springer.

Kan, A. (2009). Statistical procedures on measurement results. In the H. Atilgan (Ed.), Assessment and evaluation in education (pp.397-456). Ani Publications.

Kaplan, D., \& Glass, L. (1995). Understanding nonlinear dynamics. Springer-Verlag.

Kivunja, C. (2014). Do you want your students to be job-ready with 21 st century skills? Change pedagogies: A paradigm shift from Vygotskyian social constructivism to critical thinking, problem solving and Siemens' digital connectivism. International Journal of Higher Education, 3(3), 81-91.

Koehler, M. J., \& Mishra, P. (2009). What is technological pedagogical content knowledge? Contemporary Issues in Technology and Teacher Education, 9(1), 60-70.

Larson, K. R. (2014). Critical pedagogy(ies) for ELT in Indonesia. TEFLIN Journal, 25(1), 122-138. 
Lasagabaster, D., \& Sierra, J. M. (2010). Immersion and CLIL in English: More differences than similarities. ELT Journal, 64(4), 367-375.

Lee, J. K. (2008). Toward democracy: Social studies and TPCK. In the AACTE Committee on Innovation and Technology (Ed.), Handbook of technological pedagogical content knowledge (TPCK) for educators (pp. 129-144). Routledge.

Maljers, A., Marsh, D., Wolff, D., Genesee, F., Frigols- Martín, M., \& Mehisto, P. (2010). Diverse contexts-converging goals: CLIL in Europe. Peter Lang.

Marsh, D. (2002). CLIL-EMILE - The European dimension: Actions, trends and foresight potential. European Commission.

Marsh, D. (2015). Content and language integrated learning (CLIL): A development trajectory. Graz: EXML.

McGarr, O., \& McDonagh, A. (2019). Digital competence in teacher education, Output 1 of the Erasmus + funded Developing Student Teachers' Digital Competence (DiCTE) project. Retrieved 29 October, 2020 from https://dicte.oslomet.no/

Mehlinger, H. D., \& Powers, S. M. (2002). Technology and teacher education: A guide for educators and policymakers. Houghton Mifflin.

Mishra, P., \& Koehler, M. J. (2006). Technological pedagogical content knowledge: A framework for teacher knowledge. Teachers College Record, 108(6), 1017-1054.

Montalto, S. A., Walter, L., Theodorou, M., \& Chrysanthou, K. (2016). The CLIL guidebook. lifelong learning programme. CLIL4U. Retrieved 21 July, 2020 from www.languages.dk/archive/clil4u/ book/CLIL Book En.pdf

Moon, B. (2014). The literacy skills of secondary teaching undergraduates: Results of diagnostic testing and a discussion of findings. Australian Journal of Teacher Education, 39(12), 111-130.

Naves, T. (2002). What are the characteristics of successful CLIL programmes? In G. Langé (Ed.), TIECLIL professional development course (pp. 91-94). M.I.U.R.

New normal. (n.d.). In Collins English Dictionary. Retrieved September 10, 2020, from https://www.colli nsdictionary.com/dictionary/english/the-new-normal

New normal. (n.d.). In Oxford Lexico dictionary. Retrieved September 10, 2020, from https://www.lexico.com/definition/the_new_normal

Ng, W., \& Nicholas, H. (2013). A framework for sustainable mobile learning in schools. British Journal of Educational Technology, 44(5), 695-715.

Office of the Higher Education commission. (2019). Thai qualifications framework for higher education. B.E. 2562. Retrieved 12 June, 2020 from http://www.mua.go.th/users/tqf-hed

Pavesi, M., Bertocchi, D., Hofmannová, M., \& Kazianka, M. (2001). Teaching through a foreign language: A guide for teachers and schools to using foreign languages in content teaching. TIE CLIL.

Pimmer, C., Mateescu, M., \& Gröhbiel, U. (2016). Mobile and ubiquitous learning in higher education settings. A systematic review of empirical studies. Computers in Human Behavior, 63, 490-501.

Ponce Gea, A. I., Rico Gómez, M. L., Sola Reche, J. M., \& García Vidal, M. (2021). teacher training about information and communication technologies: A diachronic perspective. Revista ESPACIOS, 42(1), 189-200.

Smith, R. C., Kim, S., \& McIntyre, L. (2016). Relationships between prospective middle grades mathematics teachers' beliefs and TPACK. Canadian Journal of Science, Mathematics and Technology Education, 16(4), 359-373.

Son, J., Park, S., \& Park, M. (2017). Digital literacy of language learners in two different contexts. The JALT CALL Journal, 13(2), 77-96.

Stoilescu, D. (2015). A critical examination of the technological pedagogical content knowledge framework: Secondary school mathematics teachers integrating technology. Journal of Educational Computing Research, 52(4), 514-547.

TESOL International Association (TESOL). (2010). TESOL/NCATE standards for the recognition of initial TESOL programs in P-12 ESL teacher education. TESOL International Association.

TESOL International Association (TESOL). (2019). Standards for initial TESOL Pre-K-12 teacher preparation programs. Author.

Tondeur, J., Aesaert, K., Pynoo, B., Braak, J., Fraeyman, N., \& Erstad, O. (2017). Developing a validated instrument to measure preservice teachers' ICT competencies: Meeting the demands of the 21st century. British Journal of Educational Technology, 48(2), 462-472.

Tria, J. Z. (2020). The COVID-19 pandemic through the lens of education in the Philippines: The new normal. International Journal of Pedagogical Development and Lifelong Learning, 1(1), ep2001. 
United Nations Educational, Scientific and Cultural Organization (UNESCO). (2020). UNESCO report, 'COVID-19 educational disruption and response'. Retrieved 30 December, 2020 from https://en. unesco.org/covid19/educationresponse/

Wolff, D. (2012). The European framework for CLIL teacher education. Synergies Italie, 8, 105-116.

Yu, P. W. D., \& Golden, J. (2019). Developing TPACK in elementary mathematics education: A framework to design activities with pre-service teachers. In M. L. Niess, H. Gillow-Wiles, \& C. Angeli (Eds.), Handbook of research on TPACK in the digital age (pp. 47-68). IGI Global.

Publisher's Note Springer Nature remains neutral with regard to jurisdictional claims in published maps and institutional affiliations. 